\title{
The Effects of Reading Racetracks on Sight Words Across Four Elemen- tary Students with Differing Disabilities
}

\author{
Clare T. Alexander*, Tim F. McLaughlin and K. Mark Derby \\ Department of Special Education, Gonzaga University, and Holly Cartmell, Spokane Public Schools, USA
}

\begin{abstract}
The purpose of this study was to evaluate the effects of a reading racetrack procedure to increase peed and accuracy of sight word identification. Four elementary aged students with differing disabilities served as participants. A combination multiple baseline and reversal design was used to evaluate the effectiveness of the reading racetrack procedure. Words correct, errors and words attempted were measured. This study further demonstrated that reading racetracks are an effective method to increase sight words. Some generalization to novel words was found with only one of the two students. Suggestions for future research are discussed.
\end{abstract}

Educators seem to agree that literacy is one of the most important skills a student can use to gain functional living in our society [1-9]. Having skills in literacy may prevent many students from later dropping out of school [1].

Reading skills are needed in many functions of life, both social and academic. Although many understand the importance of reading, countless school districts have become lax when it comes to promoting research-based curriculums and have settled either with the "whole language" or a "balanced reading" approach $[3,10]$. This approach hypothesizes that the process of learning to read is gained in a similar manner to how one learns to crawl (i.e. naturally). There are some who are capable of learning to read as easily as learning to maneuver their legs $[9,10]$. However, there are a growing number of students who need a more systematic approach to acquiring literacy skills [2, 11-15].

One evidence-based reading curriculum method is direct instruction $[2,13,14]$. The basic philosophical components of Direct Instruction include: (a) every child can learn to read; (b) the role is of the teacher paramount in this process; (c) small group instruction; (d) error correction; (e) scripted lessons; (f) provide ample independent practice, and (g) administer probe to check student performance. Direct instruction methods allow students to actively practice skills by oneself or with partners in a very systematic manner. Direct Instruction also emphasizes frequent teacher-student interaction guided by carefully sequenced lessons utilizing learning principles and advanced programming strategies [16]. The two major rules of Direct Instruction are to "teach more in less time", and to "control the details of what happens" [17]. More is taught, by giving instruction with small groups when possible; maintaining a quick pace for active responding, developing strategies that can be taught on a limited number of examples but generalized to a large set of new examples, providing immediate and positive corrections, and sequencing instruction carefully to build on preskills, consistencies, review, and high utility applications [13]. The details of

*Address correspondence to this author at the Department of Special Education, Gonzaga University, Spokane, WA 99258-0025, USA;

E-mail: calexand@gonzaga.edu instruction are controlled by providing scripted lessons, close supervision and teacher training [15], continuous progress testing, and detailed procedural manuals for teachers, supervisors, administrators, and parents [15]. Direct Instruction implements the systematic use of positive consequences to strengthen children's motivation for learning, including: knowledge of results, behavior-specific praise, enjoyable games, and point systems [15]. In addition, many of the components of direct instruction can be modified and employed with other curricula to increase student academic responding [2, 18-23].

Reading racetracks utilize active student responding procedures combined with direct instruction and precision teaching methodology [24]. Students are timed and graph their own performance. This procedure makes use of a racetrack that has 28 different cells that can be filled with individual sight words [6] or math problems [25]. Other important components of this procedure include, timing, student self-charting, use of a model, lead, test and retest error correction procedure, and employing sight words that are visually and/or phonetically dissimilar [6, 26-28]. A sample reading racetrack can be seen in Fig. (1).

The current study focuses on the use of reading racetracks with four students, three male and one female, with differing disabilities. Their ages ranged from 7 to 9 years. The various diagnostic categories included autism, fetal alcohol effects (FAE), mental retardation (MR), severe learning disabilities (LD), behavior disorders (BD), and other health impaired (OHI). Each of the four students displayed poor reading skills and had a limited vocabulary. Another purpose of the research was to employ and extend a reading racetrack procedure [6] for students having more severe disabilities than those employed in earlier research.

\section{METHODS}

\section{Participant and Setting}

The participants in this study were all enrolled in a selfcontained elementary classroom. Student A was a 9 year-old male diagnosed with mental retardation (MR). His IQ was 67. He was in third grade and attended a self-contained class- 


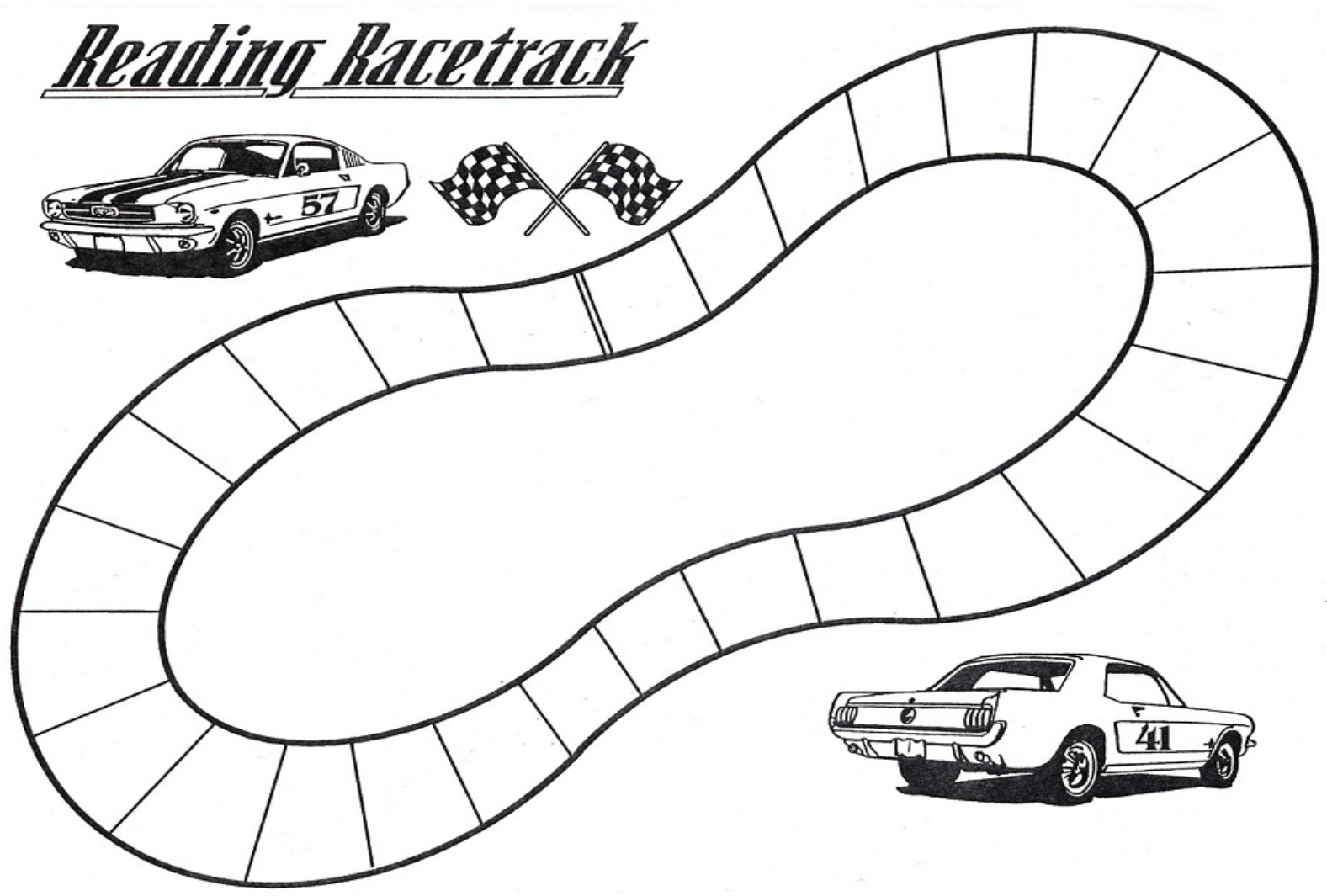

Fig. (1). Example of a Reading Racetrack paper.

room, resource-room, and integrated third grade generaleducation classroom during the school day. Student B was an 8-year-old male diagnosed with health impairments and $\mathrm{Fe}$ tal Alcohol Effects (FAE). He was in the third grade and attended a self-contained classroom with integration into a second grade general-education classroom during the school day. Student $\mathrm{C}$ was an-8-year-old male diagnosed with autism. He engaged in low rates of aberrant behavior, but would repeat instructions. He was verbal, but lacked typical social skills found in most first grade students. He was enrolled in the second grade and attended a self-contained classroom as well as being integrated into a first grade general-education classroom for non-academic activities during the school day. Student D was an 8-year-old female diagnosed with severe learning disabilities (LD) and behavior disorders (BD). She was enrolled in the second grade, but attended a self-contained classroom throughout the school day. In the past she engaged in high rates of off-task and inappropriate social behaviors. All students were deficient in the area of reading and were chosen because of their academic needs. They ability levels ranged from pre kindergarten to beginning first grade.

This study was conducted in a self-contained elementary special education classroom. There was an average of six other students with disabilities in the classroom environment. Diagnostic categories found in the classroom included cerebral palsy, autism, learning disabilities, mental retardation, and fetal alcohol syndrome. There was one certified teacher and three instructional aides to help the students with their academic and life skills curriculum. All of the students' daily classroom activities utilized tables and desks that were set up for individual, small group, and whole group instruction.

Preference assessments [29] were conducted for each student to determine their preferred rewards. Each was provided with a variety of choices and the following was found. Student A chose Play Station time. Student B chose either Play Station time or candy. Student C liked stickers, time with toy cars, or, after a change in diet, gluten and dairy free chocolate chips. Student D preferred classroom points or computer time.

\section{Materials}

A different colored laminated picture of a reading racetrack was used for each student (see Fig. 1). In addition to the reading racetrack sheets, pre/post-test sheets of sight words, toy racecars, pencils, over-head markers, and preferred rewards such as: small candies, play station time, computer time, and playing with cars were employed. Points for the classroom token economy [30] were also used to provide consequences for student progress. To keep track of time, the first author used digital kitchen timers. Data were collected using pre-made data sheets of paper that had each student's sight words typed in columns (see Fig. 2) and modified standard celeration charts [24].

\section{Dependent Variables}

There were three dependent variables. The first two of the target measures was the number of correct or error words. Each of the participants had different words based on their pretest performance from the basic word lists from the district core word lists. Fifteen sight words, which were not 
mastered during pretesting, were chosen for each student. During the reading racetracks procedure each of the participant's reading speed (words attempted) was also gathered.

\section{Student C Test Sheet}

$\begin{array}{ll}\text { stop } & \text { and for } \\ \text { yes } & \text { are } \\ \text { dad } & \text { as } \\ \text { no } & \text { at } \\ \text { go } & \text { be } \\ \text { a } & \text { but } \\ \text { all } & \text { by }\end{array}$

Fig. (2). Example of sight words in columns for pre and posttests.

\section{Data Collection and Interobserver Agreement}

The first author used a one-minute timing to measure correct and error rate, as well as reading speed for each student. The number of cells was counted on the racetrack that the student read to calculate the students' reading speed (words attempted). Event recording was used to record accuracy and errors for each student. Pre/ and post-test data were also taken during each session with each student. For pre/ and post-testing the first author timed the student for one minute and marked $\mathrm{a}+$ next to each correctly read word and a - next to each word skipped or pronounced incorrectly. These words were placed on the same sheet of words as the pre/post-test for each student. The first author summed corrects and errors from the pre and post-tests for each participant, and then divided by two to calculate the average for each session.

An instructional assistant in the classroom or the master teacher took inter-observer agreement. These data were taken in both baseline and intervention for a total of $17 \%$ of the sessions. These data were taken for each participant. The first author sat beside the student working, while the second observer marked corrects and errors on an identical recording sheet. After the pre- and posttests, the first author and the other observer compared their scores. The formula for computing interobserver agreement was the smaller number divided by the larger number and multiplying that number by 100. Reliability was $100 \%$ over the duration of the study across all participants.

\section{Experimental Design and Conditions}

The intervention was evaluated using a combination ABCDEAE and multiple baseline design [31, 32]. The design was implemented beginning with two sessions of baseline for Students A and B, three sessions of baseline for Student $\mathrm{C}$, and four sessions of baseline for Student D. After baseline data stabilized, intervention began for Student A and $\mathrm{B}$ during session number three, session number four for Student C, and session number five for Student D. Each intervention session lasted approximately 10 minutes, depend- ing on student performance. The reading racetrack was completed over 60 days and 17 or 18 sessions. A return to baseline was also conducted on session 16 for Student A and session 17 for Student B.

Baseline $1(\boldsymbol{A})$. The first author worked with each participant at a designated table or floor space, separated from the other students and educators in the classroom. Participants were asked to gather materials that were needed for completing their reading lessons. The participants were seated next to the first author at either the table or on the floor during baseline sessions. These data were taken at least 4 feet from the other students. An individualized list of sight words was given to Students A, B, C, and D to read for one minute. Each student was asked to read the words to the best of their ability and continue re-reading them until the timer sounded. They received no feedback on their accuracy or errors. The first author told the participants to "Please read the words as fast as you can and try them even if you don't know the answer." After completing each session, the first author thanked the student for all of their hard work and transitioned them to a different activity. The students' scores plotted individually on a modified standard celeration chart by the student [24] and these data were also placed on simple dated data sheets.

Reading Racetracks 1-4 (B, C, D, E). Reading racetracks were employed with many of the same procedures for the students as baseline. However, the sight words for each student were individualized. The same procedures that were used as in baseline for the pretest were employed with reading racetracks. After the one- minute time trial ended, the student was introduced to his or her own racetrack. The racetrack included from three to four new sight words, chosen from the pretest. The words were written in a repetitious manner around each racetrack. The first author was careful to not place auditory or visually similar words next to each other on the racetrack. Each new racetrack included the new words to be taught and those that had been previously employed. This was done to maintain accuracy and develop possible generalization of treatment effects.

After receiving their racetrack, each student would read over and practice each word with the first author. When the student said, "I am ready", the first author would have them point to the first word on the track to prepare themselves. If a word was stated accurately, the student moved on to the next word cell. If a word was stated incorrectly, the first author would restate the word correctly using the model, lead, test procedure. When the word was on the track, a retest took place. If the child self-corrected, he/she immediately moved on to the next word. If the student did not know the word they would say, "I don't know". The first author would help them, again using the model, lead, test, and retest procedure. If there was more than a three second delay in vocalizing, or attempting to vocalize the word, the first author would use the model, lead, and test procedure. After one minute, the student would then count, with the first author, the number of word cells that they read and record their corrects and errors on their data form and standard celeration chart.

Baseline 2 (Probes) (A). For participants A and B, a probe procedure was employed to determine if employing of the reading racetrack procedure, would generalize to new set of untrained words. 


\section{Reading Racetrack}

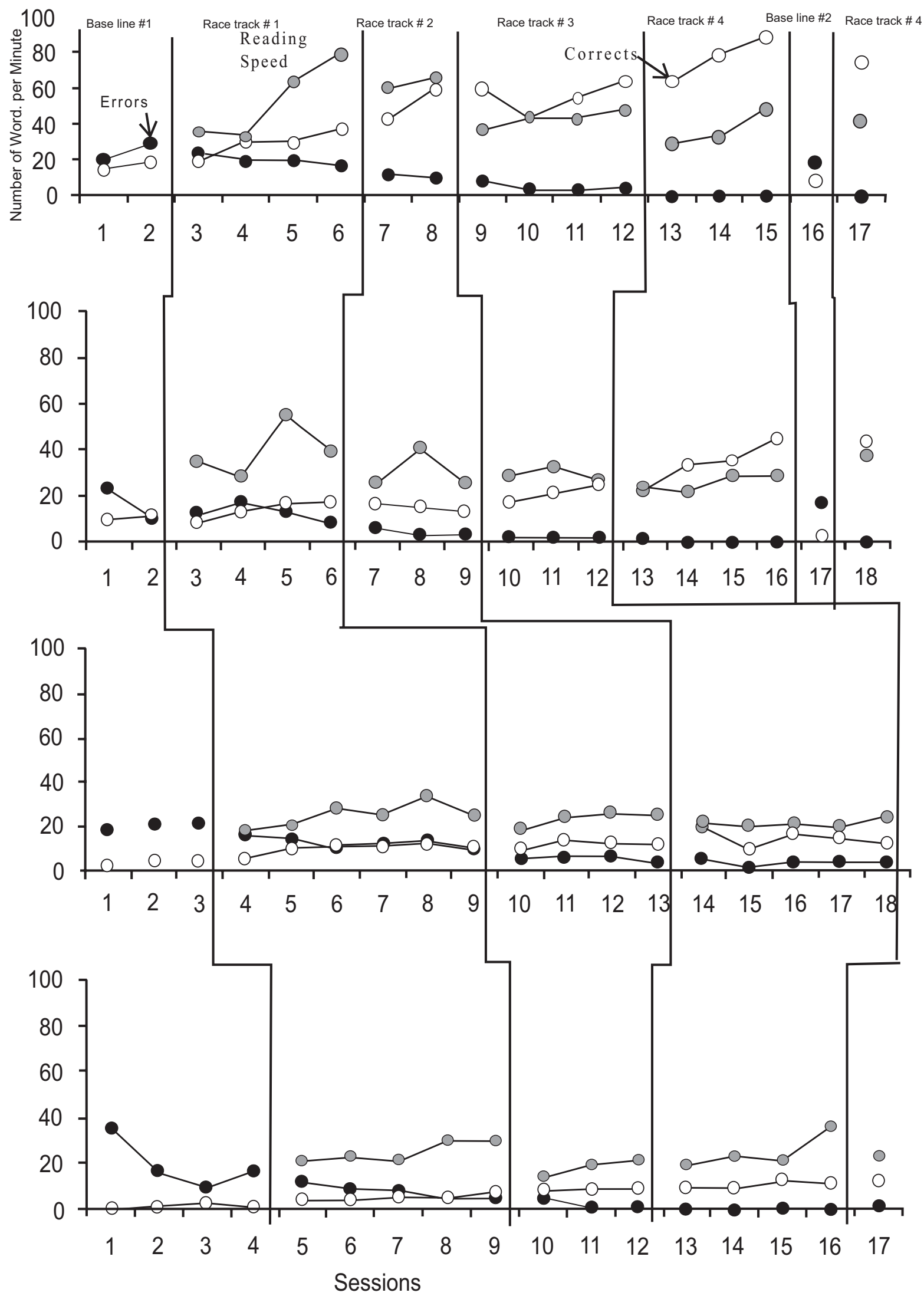

Fig. (3). The number of corrects (open circles) and errors (closed circles) during for each experimental condition for each participant. The number of words attempted (reading speed) is shown as grey circles for participants $\mathbf{A}$ through $\mathbf{D}$. 


\section{RESULTS}

The outcomes for the students are presented in Fig. (3) for each of the participants.

\section{Baseline}

Student A had an average of 17 corrects and 25 errors for baseline 1. Student B averaged 10.8 corrects and 16.5 errors during baseline 1 . Student $C$ had an average of 3.7 corrects and 20.7 errors for this baseline. Student D had an average of 1.5 corrects and 19.6 errors during baseline 1 .

\section{Reading Racetrack 1-4}

Each student improved their performance during reading racetracks. Student A averaged 29.3 corrects and 20.1 errors for reading racetrack \#1. Student A's correct rate 52.9 words per minute. Student B increased his corrects to an average of 13.6 with 12.3 errors. His reading speed averaged 39.3 words per minute. Student $C$ increased his corrects to a mean of 10.4 and his errors declined ( $M=12.8$ errors). His reading speed increased and averaged 25.5 words per minute. Student D had an average of just of 5.2 corrects with 7.8 errors. This participant's reading speed was 25.1 words per minute.

During reading racetrack \#2, Student A had an average of 51.5 corrects, with 10.8 errors. His fluency increased to 63.3 words per minute. Student B had an average of 14.5 corrects, 5.5 errors, and 30.0 words per minute for reading racetrack \#2. Student C averaged 12.1 corrects with 6 errors. His fluency was 23.4 words per minute. Student D averaged of 8.7 corrects, with 2.3 errors. Her reading speed averaged 18.3 words per minute.

During reading racetrack \#3, Student A averaged 55.5 corrects, with a mean of 5.3 errors. His mean fluency declined to 43 words per minute. Student B improved his corrects to 20.7 corrects with just 1 error. His average reading speed was 29 words per minute. Student C averaged 14.9 corrects, with 4 errors on reading racetrack \#3. His mean fluency was 21.4 words per minute. Student D increased her corrects to a mean of 10.9 corrects. Her average errors declined to just 0.5 errors. Her reading speed improved to an average of 25.3 words per minute.

For reading racetrack \#4, student A's corrects again increased to a mean of 77.5 corrects, with no 0 errors. His fluency decreased slightly to 37 words per minute. Student B had an average of 49 corrects and only 0.1 errors. His fluency increased to 25.4 words correct per minute. Student C did not reach his fourth racetrack. Student D averaged 13 corrects, and just 1 error. Her fluency declined to 24 words per minute. After Baseline 2, Student A and B improved their performance for the remainder of sessions for reading racetrack \#4.

\section{Baseline 2 (Probe)}

After reading racetrack \#4, Students A and B were given a new list of 15 words as a baseline probe for one session. Generalization to new untrained sight words was low. Student A had 9 corrects and 19 errors, while Student B had just 2 corrects and 17 errors.

\section{DISCUSSION}

The present outcomes extend and replicate the use of reading racetracks to children with different as well as more severe disabilities than was employed in our prior research $[4,5,27,28]$. The present outcomes provide additional evidence that having students engage in additional drill and practice in an academic area improves student performance [5, 19-22]. Finally, the present report provides additional confirmation that precision teaching procedures can be combined with the model, lead, test, and retest error correction procedures. This adds to the evidence of our prior research indicating that Direct Instruction and precision teaching methodology can be combined to benefit student academic outcomes in literacy [33, 34].

Each student typically showed gradual improvement for both corrects and errors when reading racetracks were employed. In addition, the reading speed increased for each participant. The slight decreases in accuracy and/or speed would likely be because of the introduction of new words at the beginning of each new racetrack and the time required for error correction. This finding has been noted in all our past research with reading racetracks $[5,6,27,28]$, and in math [25]. Small increases for errors could also be attributed to the introduction of new sight words or problems as well as the time required for error correction.

Further data collection using reading racetracks should be conducted across various settings, using multiple instructors, and with a different research group. This would be a beginning in a attempt to increase the generalizability of these procedures. At this time, some of this work is taking place. In addition, the outcomes maybe attributed to additional practice rather than through the use of reading racetracks. Since employing reading racetracks produces extra practice, such an issue will have to be examined in future research.

The additional practice provided with the intervention does place a limitation on the outcomes. In the present research we were unable to separate the effects of repeated practice from the reading racetrack. That will have to done in future research. One of the advantages of reading racetracks is the additional practice they provide. There is a large amount of data regarding the effects of repeated practice [2, 16]. This is especially true if such practice is guided [2]. The use of a single case research design also requires the use of frequent measurement [31].

In the present analysis we also examined generalization of skills through the use of a baseline probe. These outcomes were disappointing in terms of generalization to new words. This important issue will have to be addressed in future research. The improvements noted in the baseline probes near the end of the research were small. One participant displayed some generalization to new words while one did not. Maybe a more active process [35] such as employing more previously mastered words on the probe would have been appropriate. Also, interspersing more of the words from previous reading racetracks may have yielded different outcomes for the second participant. Alternating two types of racetracks (one with words that will appear on the probe sheets with 
one without such words) may be a fruitful area of research. These important issues will have to be addressed in future research.

The classroom teacher agreed to continue implementing the program/procedures when there is a need and/or time for the students who participated, as well for other students who could possibly benefit from reading racetracks. This provides a small example of social validity of the procedures. The students' general education teachers were continuously notified of their progress and indicated their appreciation of the students' improvements in all target areas. A copy of the final study was given to the students' teachers and copies were also provided to parents, guardians, and/or other care providers.

\section{ACKNOWLEDGEMENTS}

This research was completed in partial fulfillment for the Bachelor of Education in Special Education at Gonzaga University. The first author would like to thank the participants for their cooperation and enthusiasm for learning. Also, the first author would like to extend her gratitude toward the cooperating teachers for their assistance and guidance throughout this study.

\section{REFERENCES}

[1] Chambers D, Dunn C, Rabren K. Variables affecting students' decisions to drop out of school. Rem Spec Educ 2004; 25: 314-25.

[2] Marchand-Martella NE, Slocum TA, Martella R, Eds. Introduction to direct instruction. Boston, MA: Pearson Education, Inc. 2004.

[3] National Reading Panel. Teaching children to read: An evidencebased assessment of the scientific research literature on reading and its implications for reading instruction 2000. Available on-line: http://www.nichd.nih. gov/publications/nrp/smallbook.html

[4] National Research Council. Preventing reading difficulties in young children. Washington DC: National Academy Press, Author 1998.

[5] Rinaldi L, McLaughlin TF. The effects of reading racetracks on the fluency of see-to-say words in isolation by a student with learning disabilities. J Prec Teach Celebr 1996; 13(2): 44-52.

[6] Rinaldi L, Sells D, McLaughlin TF. The effects of reading racetracks on the sight word acquisition and fluency of elementary students. J Behav Educ 1997; 7: 219-33.

[7] Slavin RE. Education for all. Exton PA. Swets \& Zeitlinger Publishers 1996.

[8] Sweeney WJ, Omness CK, Janusz CK, Cooper JO. Adult literacy and precision teaching: repeated readings and see/cover/write practice to improve reading and spelling. J Prec Teach 1996; 9(1): 6-19.

[9] Weaver C. Understanding whole language. Portsmouth, NH: Heinemann 1990

[10] Liberman IY, Liberman AM. Whole language vs code emphasis: underlying assumptions and their implications for reading instruction. Annal Dyslex 1990; 40: 51-76.

[11] Adams MJ. Beginning to read: thinking and learning about print. Cambridge MA: MIT Press 1990.

[12] Adams MJ. Beginning to read: A critique by literacy professionals. Read Teach 1991; 44: 371-72.
[13] Carnine D, Silbert J, Kameenui EJ. Direct instruction reading. Columbus OH: Merrill Publishing Co. 1990.

[14] Carnine D, Silbert J, Kameenui EJ, Tarver S. Direct instruction reading, 4th ed. Upper Saddle River NJ: Pearson Publishing 2004.

[15] Engelmann S. The logic and facts of effective supervision. Educ Treat Child 1988; 11: 328-40.

[16] Engelmann S, Carnine D. Theory of instruction. New York: Irvington 1992.

[17] Engelmann S, Becker WC, Carnine D, Gersten R. The direct instruction follow through model: Design and outcomes. Educ Treat Child 1988: 11: 303-17.

[18] Barbetta PM, Heron TE, Heward WL. Effects of active student response during error correction on the acquisition, maintenance, and generalization of sight words by students with developmental disabilities. J Appl Behav Anal 1993; 26: 111-120.

[19] Barbetta PM, Heward WL, Bradley DM. Relative effects of wholeword and phonetic-prompt error correction on the acquisition and maintenance of sight words by students with developmental disabilities. J Appl Behav Anal 1993; 26: 99-110.

[20] Greenwood CA, Delquadri J, Hall RV. Longitudinal effects of classwide peer tutoring. J Educ Psychol 1989; 81: 371-83.

[21] Greenwood CA, Dinwiddie G, Bailey, et al. Field replication of classwide peer tutoring. J Appl Behav Anal 1987; 20: 151-60.

[22] Greenwood CA, Hart B, Walker D, Risley TR. The opportunity to respond and academic performance revisited: A behavioral theory of developmental retardation and its prevention. In: Gardner R III, Sainato D, Cooper JO, et al. Eds. Behavior analysis in education: focus on measurably superior instruction. Pacific Grove, CA: Brooks/Cole; pp. 213-23

[23] Shapiro ES. Academic skill problems: direct assessment and intervention. New York: Guilford 1996.

[24] Lindsley OR. Precision teaching's unique legacy from B. F. Skinner. J Behav Educ 1991; 1: 253-66.

[25] Beveridge B, Weber KP, Derby KM, McLaughlin TF. The effects of a math racetrack with two elementary students with learning disabilities. Int J Spec Educ 2005; 20(2): 58-65.

[26] Anthony C, Rinaldi l, Hern C, McLaughlin TF. Reading racetracks: A direct replication and analysis with three elementary students. J Prec Teach Celebr 1997; 14(2): 31-6.

[27] Falk M, Band M, McLaughlin TF. The effects of reading racetracks and flashcards on sight word vocabulary of three third grade students with a specific learning disability: A further replication and analysis. Int J Spec Educ 2003; 18(2): 51-7.

[28] Printz K, McLaughlin TF, Band M. The effects of reading racetracks and flashcards on sight word vocabulary: A case report and replication. Int J Spec Educ 2006; 21(1): 103-8.

[29] Alberto P, Troutman AG. Applied behavior analysis for teachers. 7th ed. Upper Saddle River, NJ: Prentice Hall-Merrill 2006.

[30] McLaughlin TF, Williams RL. The token economy in the classroom. In: Witt JC, Elliott JC, Gresham FM Eds. Handbook of behavior therapy in education, New York: Plenum 1988; pp. 469-487.

[31] Kazdin AE. Single case research designs: Methods for clinical and applies settings. New York: Oxford University Press 1982.

[32] Tawney J, Gast DL. Single subject research in special education. Columbus OH: Merrill 1984

[33] Gregory A, McLaughlin TF, Weber KP, Stookey S. The effects of using direct instruction and a re-reading contingency with a high school student. Int J Spec Educ 2005: 20(1): 50-4.

[34] Holz KR, Peck SM, McLaughlin TF, Stookey S. The effects of using direct instruction reading and a re-reading contingency coupled with a reward and praise contingency with a high school sophomore. J Prec Teach Celebr 1996: 14(1): 35-40.

[35] Stokes TF, Baer DM. An implicit technology of generalization. J Appl Behav Anal 1977; 10: 349-67. 